\title{
TRAJETÓRIA ACADÊMICA E INSERCÂO PROFISSIONAL DE DOCENTES EM TEMPOS DE REESTRUTURAÇÃO PRODUTIVA
}

\author{
ACADEMIC TRAJECTORY AND EMPLOYABILITY OF TEACHERS ON PRODUCTIVE \\ RESTRUCTURING TIMES \\ CARRERA ACADÉMICA Y LA EMPLEABILIDAD DE LOS DOCENTES EN TIEMPOS \\ DE REESTRUCTURACIÓN PRODUCTIVA
}

Leandro Turmena*

leandroturmena@utfpr.edu.br

Vânia Maria Alves ${ }^{* *}$

vania.alves@ifpr.edu.br

RESUMO: Este estudo analisa a trajetória acadêmica e sua relação como o ingresso profissional dos docentes que assumiram o concurso público no Instituto Federal do Paraná (IFPR) - Campus Palmas, no ano de 2010. Os dados indicam que a trajetória acadêmica se deu, na sua maioria, em instituições públicas que, provavelmente, integram em suas atividades formativas o ensino, a pesquisa e a extensão. Alinhado às mudanças ocorridas no mundo do trabalho, no Brasil, nas últimas décadas, verificou-se, também, que a exigência (titulacão e habilidades) explicitada em edital é de que o trabalhador docente tenha característica generalista.

Palavras-chave: Formação Docente. Inserção Profissional. Reestruturação Produtiva.

ABSTRACT: This study analyzes the academic trajectory and its relationship such as the professional entry of teachers who took the public tender at the Federal Institute of Paraná (IFPR) - Campus Palmas, in 2010. The data indicate that the academic life occurred mostly in public institutions that are likely to integrate in their educational activities teaching, research and extension.
In line with changes in the world of work, in Brazil, in recent decades, it was also verified that the requirements (titles and skills), explicit in the public notice, is that teachers have a generalist characteristic.

Keywords: Teacher Education. Employability. Productive Restructuring.

RESUMEN: Examina la carrera académica y su relación como la entrada profesional de los docentes que tomaron la licitación en el Instituto Federal de Paraná (IFPR) Campus Palmas, en el año 2010. Los datos indican que la carrera académica tomó su mayoría en las instituciones públicas que puedan integrar en su enseñanza actividades educativas, de investigación y extensión. En línea con los cambios en el mundo del trabajo en Brasil en las últimas décadas, también hubo la exigencia (titulación y habilidades), el aviso es explícito en ese trabajador maestros tiene característica generalista.

Palabras clave: Formación del profesorado. Empleabilidad. Reestructuración productiva. 


\footnotetext{
* Doutorado em Educação pela Universidade Estadual de Maringá (UEM). Docente da Universidade Tecnológica Federal do Paraná (UTFPR) Campus de Dois Vizinhos.

** Doutora em Educação pela Universidade Federal de Santa Catarina (UFSC). Docente do Instituto Federal do Paraná (IFPR) Campus Palmas.
}

\section{INTRODUÇÃO}

O objetivo desta pesquisa é analisar a trajetória acadêmica e sua relação com o ingresso profissional dos docentes que assumiram o concurso público no Instituto $\mathrm{Fe}$ deral do Paraná (IFPR) - Campus Palmas, no ano de 2010, problematizando as coerências e contradições existentes nesse processo. Para tanto, realizamos levantamento através do currículo lattes dos docentes visando à coleta de informações sobre a trajetória - graduação e pós-graduação, lato e stricto sensu -, bem como as instituições nas quais obtiveram a titulação. A análise do edital do concurso que estes profissionais prestaram também compôs esta etapa. A posteriori, fizemos pesquisa bibliográfica, para fundamentar teoricamente a análise do objeto de pesquisa, no intuito de aprofundar a discussão dos aspectos de formação acadêmica que contribuíram para a inserção profissional dos docentes. Consideramos que a formação/titulação e a trajetória acadêmica dos docentes foram fundamentais para o ingresso no IFPR e que, neste caso, as exigências para o trabalho docente se articulam às mudanças no mundo do trabalho, visto que neste uma das características centrais é a flexibilização.

\section{TRAJETÓRIA ACADÊMICA E INSERÇÃO PROFISSIONAL}

Antes de adentrar na discussão referente à trajetória acadêmica e ao ingresso profissional dos docentes que assumiram o concurso público no IFPR - Campus Palmas, no ano de 2010, torna-se necessário situarmos a inserção dessa instituição no Município de Palmas, região Sudoeste do Paraná.

A implantação do Ensino Superior no Sudoeste do Paraná ocorreu no município de Palmas (primeira cidade da região) com a fundação da Faculdade de Filosofia, Ciências e Letras de Palmas (FAFI), em 1967, já com um caráter confessional. A instituição foi criada pela Igreja Católica, intermediada pela Fundação do Centro Pastoral, Educacional Dom Carlos (CPEA).

Em 1979, 12 anos mais tarde, foi fundada a instituição Faculdades Reunidas de Administração, Ciências Contábeis e Ciências Econômicas de Palmas (FACEPAL), mantida pelo Poder Executivo Municipal em parceria com o CPEA (LIMA, 1997), o que desencadeou no surgimento das Faculdades Integradas Católicas de Palmas (FACIPAL) em 2001, com a junção da FAFI e da FACEPAL. Essa mesma instituição, em 17 de maio de 2004, foi transformada em Centro Universitário Diocesano do Sudoeste do Paraná (UNICS) mudando em 2008 sua nomenclatura para Centro Universitário Católico do Sudoeste do Paraná (UNICS).

De acordo com Lima (1997, p. 12), a fundação da FAFI, com cursos na área de licenciatura, esteve atrelada à 
${ }^{1}$ É importante enfatizarmos que, historicamente, a Igreja Católica buscou recursos do Estado para financiar a iniciativa privada (escolas confessionais). O debate que precedeu a Lei de Diretrizes e Bases da Educação Nacional (LDBEN) - Lei $n^{\circ} 4.024$, de 20 de dezembro de_1961 (BRASIL, 1961) é um bom exemplo. Também devemos salientar que segmentos conservadores do catolicismo apoiaram o Golpe de 1964, da mesma forma que segmentos minoritários se colocaram contra a Ditadura civil militar. preocupação por parte do "grupo de pioneiros com a educação e com a formação de professores na região". Segundo a mesma autora, outra preocupação despontou na fundação da FACEPAL, pois era necessária a criação de outros cursos evitando, assim, "[...] a evasão de centenas de jovens de Palmas e da região para outras cidades e estados; e devido também à existência de mercado de trabalho na região e seu consequente aumento de divisas" (LIMA, 1997, p. 13, grifos nossos).

A criação de uma Instituição de Ensino Superior (IES) na cidade de Palmas se articula com as necessidades, em termos de formação profissional, demandadas pela população do município, que já contava com 27 mil habitantes, bem como, da região, uma vez que não existiam IES que atendessem às necessidades de um mercado de trabalho em expansão. Nesse caso, percebe-se a "aliança" feita entre a Igreja Católica ${ }^{1}$ com o Estado ditatorial, na aplicabilidade de recursos públicos à iniciativa privada, com a pretensão de formar a população através da educação como requisito de capital humano para atender à procura do mercado de trabalho, do capital competitivo em expansão, formando profissionais das áreas "vocacionadas", local e regionalmente.

No início da década de 1990, houve uma tentativa (via governo estadual) de criar a Fundação Universidade Estadual do Vale do Iguaçu - UNIVALE com sede na cidade de Palmas que abarcaria a FAFI e a Faculdade da Cidade de União da Vitória (FACE), de União da Vitória/PR; a FAFI e FACEPAL, de Palmas/TO, a Fundação de Ensino Superior de Pato Branco (FUNESP), de Pato Branco/PR, e a Faculdade de Ciências Humanas de Francisco Beltrão (FACIBEL), de Francisco Beltrão/PR. As discussões estavam bem avançadas; porém, a partir do momento em que Roberto Requião (1991-1994) assumiu o governo do Estado, o discurso da falta de recursos tornou-se um fator desfavorável ao investimento em educação superior pública estadual, o que impediu a criação da UNIVALE. Segundo Lima (1997, p. 16), “[...] o Estado do Paraná não dispunha de recursos suficientes para absorver mais gastos com o Ensino Superior e que mais uma universidade, englobando seis faculdades, era totalmente inviável". Todavia, segundo essa autora, o governo do Estado forneceu apoio financeiro para as faculdades de Palmas e Francisco Beltrão uma vez que a faculdade de União da Vitória já estava estatizada e a de Pato Branco com o processo bem adiantado de federalização.

A partir das políticas de expansão da educação pública federal, o governo instituiu a Rede Federal de Educação Profissional, Científica e Tecnológica, criando os Institutos Federais de Educação, Ciência e Tecnologia (Lei no ${ }^{0} 11.892$, de 29 de dezembro de 2008). Foi nesse contexto que, no início de 2009, a administração do CPEA/UNICS, passou a focar na sua inclusão ao Instituto Federal de Educação, Ciência e Tecnologia do Paraná. Iniciativa esta que contou 
${ }^{2}$ Cursos que foram incorporados pelo IFPR: Administração, Agronomia, Artes visuais, Ciências Biológicas, Ciências Contábeis, Direito, Educação Física, Enfermagem, Engenharia Civil, Farmácia, Letras, Pedagogia, Química, Sistemas de Informação e Tecnologia Agroflorestal.

${ }^{3}$ Foram incorporados, pelo IFPR, 970 alunos oriundos do UNICS e mais 280 alunos que preencheram as vagas através de editais específicos. O IFPR iniciou suas atividades em Palmas com um total de 1.250 alunos, distribuídos nos diversos cursos mencionados. com a integração de lideranças políticas locais, regionais e nacionais, pessoas representativas de diversos movimentos e associações.

A federalização ocorreu em 17 de março de 2010, quando aconteceu o ato oficial de desapropriação dos bens imóveis e laboratoriais do UNICS e, a instalação do Instituto de Educação, Ciência e Tecnologia do Paraná (IFPR) Complexo Tecnológico D. Agostinho José Sartori. Cabe destacarmos que, no dia 14 de junho de 2010, a Secretaria de Educação Superior do Ministério de Educação, através da Portaria $\mathrm{n}^{0} 728 / 2010$, publicada no DOU n ${ }^{0} 112$ de 15 de junho de 2010, aprovou a incorporação dos cursos ${ }^{2} \mathrm{e}$ alunos $^{3}$ pelo IFPR, e declarou extinto o UNICS.

Para suprir a demanda de servidores professores e técnicos administrativos, foram abertos concursos públicos em diferentes etapas. No ano de 2010, foram publicados os Editais do PROGEPE/IFPR de números oo6/2010, o08/2010, 013/2010 e 033/2010 - Concurso Público para provimento de cargos de professor da Carreira do Ensino Básico, Técnico e Tecnológico, Classe "D I", Nível 1, preenchendo o número de vagas para docentes, conforme aponta o Quadro 1.

No intuito de estudar a trajetória acadêmica e o ingresso profissional dos docentes que assumiram o Concurso Público no IFPR - Campus Palmas, no ano de 2010, de acordo com os editais elencados, analisamos o currículo lattes desses profissionais. No total, foram 57 (cinquenta e sete) os docentes que ingressaram na carreira do magistério nessa instituição. A seguir, na Tabela 1, apresentamos as diversas áreas do conhecimento e o número de docentes concursados em cada área, conforme demanda apresentada na época da federalização.

Tabela 1 - Número de docentes por área do conhecimento

\begin{tabular}{lc}
\hline Áreas do conhecimento & Número de docentes \\
\hline Ciências Biológicas & 04 \\
Administração & 05 \\
Sistemas de Informação & 03 \\
Educação Física & 04 \\
Artes & 03 \\
Direito & 05 \\
Química & 04 \\
Pedagogia & 04 \\
Matemática & 01 \\
Letras & 03 \\
Engenharia Civil & 02 \\
Enfermagem & 06 \\
Farmácia & 04 \\
Ciências Contábeis & 02 \\
Agronomia & 07 \\
\hline TOTAL & 57 \\
\hline
\end{tabular}

Fonte: Dados organizados pelos autores com base na pesquisa realizada. 
${ }^{4}$ Segundo Alves (2008), as universidades consolidadas são aquelas nas quais a pesquisa já está consolidada, através de uma produção intelectual institucionalizada, em geral, mantendo Programas de Pós-Graduação Stricto Sensu. Ou ainda, de acordo com a Lei no 9.394/96, art. 52 (LDBEN): “As universidades são instituições pluridisciplinares de formação dos quadros profissionais de nível superior, de pesquisa, de extensão e de domínio e cultivo do saber humano que se caracterizam por: I - produção intelectual institucionalizada mediante o estudo sistemático dos temas e problemas mais relevantes, tanto do ponto de vista científico e cultural, quanto regional e nacional; II - um terço do corpo docente, pelo menos, com titulação acadêmica de mestrado ou doutorado; III - um terço do corpo docente em regime de tempo integral" (BRASIL, 1996).
Um dos nossos objetivos consiste em estudar a titulação/formação acadêmica dos docentes ingressantes no IFPR - Campus Palmas, no ano de 2010. Assim, de acordo com os currículos lattes dos docentes pesquisados, verificamos que a maioria dos professores possuía o título de mestre, conforme demonstra a Tabela 2, que segue:

Tabela 2 - Titulação/formação acadêmica dos docentes

\begin{tabular}{lc}
\hline Titulação/Formação acadêmica & Número de docentes \\
\hline Especialista & 08 \\
Mestrando & 05 \\
Mestre & 26 \\
Doutorando & 11 \\
Doutor & 06 \\
Pós-doutorado & 01 \\
\hline TOTAL & 57 \\
\hline
\end{tabular}

Fonte: Dados organizados pelos autores com base nos currículos lattes dos docentes pesquisados.

Além da titulação, do nível de formação escolar dos docentes, também é relevante o mapeamento da trajetória acadêmica, uma vez que um de nossos pressupostos foi o de que os docentes haviam feito sua formação em instituições consolidadas ${ }^{4}$ do ponto de vista do ensino e da pesquisa. Assim, quanto às instituições nas quais esses professores obtiveram suas titulações, ou seja, sua formação acadêmica, constatamos o seguinte cenário, conforme expressa a Tabela 3:

Tabela 3 - Instituições de Ensino Superior (IES) em que os docentes se titularam

\begin{tabular}{|c|c|c|c|c|c|c|c|}
\hline IES & Graduação & Especialização & Mestrando & Mestrado & Doutorando & Doutorado & $\begin{array}{c}\begin{array}{c}\text { Pós- } \\
\text { doutorado }\end{array} \\
\end{array}$ \\
\hline \multicolumn{8}{|l|}{ Faculdade: } \\
\hline Pública & 03 & 02 & - & - & - & - & - \\
\hline Privada & 12 & 07 & - & - & - & - & - \\
\hline $\begin{array}{l}\text { Centro Uni- } \\
\text { versitário }\end{array}$ & 05 & 07 & 01 & 05 & - & - & - \\
\hline \multicolumn{8}{|l|}{ Universidade: } \\
\hline Pública & 30 & 17 & 04 & 28 & 10 & 06 & - \\
\hline Privada & 14 & 09 & - & 08 & - & 01 & - \\
\hline $\begin{array}{l}\text { Universidade } \\
\text { Internacional }\end{array}$ & - & 01 & 01 & 01 & 01 & - & 01 \\
\hline TOTAL & $64^{5}$ & 43 & 6 & 42 & 11 & 7 & 01 \\
\hline
\end{tabular}

Fonte: Dados organizados pelos autores com base nos currículos lattes dos docentes pesquisados.

${ }^{5}$ Lembramos que o número total de docentes pesquisados foi 57 (cinquenta e sete), mas alguns docentes cursaram mais de uma graduação; por isso, o número total no item "graduação" foi de 64 (sessenta e quatro).
Os dados apresentados na Tabela 3 ratificam nossos pressupostos de que a maioria dos docentes fez a sua formação acadêmica, especialmente a pós-graduação stricto sensu, em instituições públicas consolidadas. Isso, em geral, denota a possibilidade de uma formação mais sólida, aspecto valorizado e requisitado para obter sucesso em concursos públicos.

Podemos compreender a valoração desse acúmulo de capital cultural, expresso por meio dos títulos 
${ }^{6}$ Destacamos que, neste estudo, não utilizamos o método de pesquisa delineado por esse autor. Apenas trabalhamos o conceito de capital cultural expresso nas obras referenciadas. acadêmicos, em estudos feitos pelo sociólogo francês Pierre Bourdieu ${ }^{6}$. O significado do conceito "capital cultural" é dado pelo próprio autor, quando afirma: “[...] este capital é o produto garantido dos efeitos acumulados da transmissão cultural assegurada pela família e da transmissão cultural assegurada pela escola (cuja eficácia depende da importância do capital cultural diretamente herdado da família)" (BOURDIEU, 2008, p. 27). Já Ione Ribeiro Valle (2008, p. 104) menciona que o capital cultural é constituído por “[...] saberes, competências e outras aquisições culturais [...], revela as desigualdades de desempenho segundo a classe social de origem".

Para aprofundar o significado do conceito em pauta, na obra Les trois états du capital culturel, publicada em 1979, e traduzida para o português em 2005, Bourdieu afirma que:

O capital cultural pode existir sob três formas: No estado incorporado, ou seja, sob a forma de disposições duráveis do organismo; no estado objetivado, sob a forma de bens culturais - quadros, livros, dicionários, instrumentos, máquinas, que constituem indícios ou a realização de teorias ou de críticas dessas teorias, de problemáticas, etc.; e, enfim, no estado institucionalizado, forma de objetivação que é preciso colocar à parte porque, como se observa em relação ao certificado escolar, ela confere ao capital cultural - de que é, supostamente, a garantia propriedades inteiramente originais. (2005, p. 74, grifos do autor).

Interessa-nos aqui, para aprofundar a análise sobre o nosso objeto de estudo, a saber, a valoração dos títulos dos docentes ingressantes no IFPR, no ano de 2010, a terceira forma de capital cultural, ou seja, o estado institucionalizado. A objetivação do capital cultural sob a forma de diploma, conforme Bourdieu (2005), é uma das maneiras de neutralizar certas propriedades devidas ao fato de que, estando incorporado, esse capital tem os mesmos limites biológicos de seu suporte. Com o diploma, essa certidão de competência cultural - que confere ao seu portador um valor convencional, constante e juridicamente garantido-, no que se refere à cultura, a alquimia social produz uma forma de capital cultural que possui uma autonomia relativa em relação ao seu portador e, até mesmo, em relação ao capital cultural que ele possui, efetivamente, em um determinado momento histórico. Assim: "Ela institui o capital cultural pela magia coletiva, da mesma forma que, segundo Merleau-Ponty, os vivos instituem seus mortos através dos ritos do luto" (BOURDIEU, 2005, p. 78). Continua, ainda, o autor:

Basta pensar no concurso que, a partir do continuum das diferenças infinitesimais en- 
tre as performances, produz descontinuidades duráveis e brutais, do tudo ao nada, como aquela que separa o último aprovado do primeiro reprovado, e institui uma diferença de essência entre a competência estatutariamente reconhecida e garantida e o simples capital cultural, constantemente intimado a demonstrar seu valor. Vê-se claramente, nesse caso, a magia performática do poder de instituir, poder de fazer ver e de fazer crer, ou, numa só palavra, de fazer reconhecer. (BOURDIEU, 2005, p. 78, grifos do autor).

Os estudos de Bourdieu permitem compreender a relação existente entre os títulos acadêmicos e o reconhecimento social destes. Dessa forma, vê-se claramente que os títulos dos docentes ingressantes no IFPR - Campus Palmas, no ano de 2010, em sua maioria conquistados em instituições consolidadas, são dotados de enorme reconhecimento sociocultural e institucional, fator que certamente contribuiu para que obtivessem êxito no Concurso Público. É importante lembrarmos de que nosso objetivo não era o de entrar no mérito da competência do desempenho técnico dos docentes aprovados no concurso, mas justamente fazer a análise do quanto os títulos acadêmicos são socialmente valorizados, possuem essa magia do poder de instituir, parafraseando Bourdieu (2005, p. 78), especialmente aqueles adquiridos em determinadas universidades, em geral, públicas e consolidadas.

A formação e a titulação da maioria dos sujeitos pesquisados, deu-se, portanto, em instituições que têm a pesquisa institucionalizada, em Programas Pós-Graduação Stricto Sensu. Contudo, essa não parece ser a realidade da maioria das IES como mostram os estudos de Alves (2008) e Turmena (2009); a indissociabilidade entre ensino, pesquisa e extensão, proposta desde a Reforma Universitária de 1968, sofre reformulações no modus operandi de grande parte das instituições de Ensino Superior brasileiras.

De acordo com Neves e Fernandes (2002, p. 31),

[...] somente as universidades continuariam a manter a indissociabilidade entre ensino, pesquisa e extensão como princípio educativo, enquanto todas as demais se dedicariam exclusivamente ao ensino, ou seja, à capacitação da força de trabalho para a realização das tarefas especializadas em níveis distintos de complexidade, demandadas pelo processo de difusão do novo paradigma produtivo.

Embora haja a institucionalização da pesquisa nas universidades, é importante observarmos a assertiva de Saviani (1985) ao afirmar que a universidade da produção cede lugar à universidade do consumo. Ademais, Silva Jr. (2002, p. 68), explica que a produção de conhecimento 
[...] - consubstancial à ideia de universidade desde seus primórdios - tende a ser substituída pela administração de dados e informações de um processo de assessoria ao mercado, o que impõe a sensível perda do necessário distanciamento que esta instituição deve ter em relação à sociedade, da capacidade de reflexão e crítica, característica também histórica da universidade. Este processo de substituição da produção de conhecimento pela administração de dados e informações assemelharia a instituição universitária, quando referida à sociedade, a empresas prestadoras de serviços, e quando referidas ao mercado, a uma instituição legitimadora da nova cultura política caracterizada pela adaptação, pela instrumentalidade.

Destaca-se, também, que a maioria das instituições em que os sujeitos pesquisados se formaram/titularam estão localizadas em centros urbanos maiores. Por sua vez, as universidades que se caracterizam como interioranas e regionalizadas, apresentam como meta a produção de um grande número de graduados, enfatizando prioritariamente as atividades de ensino e permitindo aos egressos a inserção imediata no mercado de trabalho (NEVES; PRONKO, 2008).

Os países centrais não desejam ter o Brasil como produtor de ciência e tecnologia, apenas como mero consumidor delas. Logicamente, não é do interesse destes países que a universidade brasileira invista na pesquisa, nem que o governo destine recursos públicos esta (BOGONI, 2002). Segundo Sobrinho (1999, p. 63), as recomendações do Banco Mundial são claras, ao afirmarem que "[...] a pesquisa é coisa para os países ricos, que já teriam os recursos materiais e humanos instalados para desenvolvê-la. Aos países pobres cumpriria a tarefa de ampliar mais qualificadamente a massa de consumidores".

Com o intuito de adequar a universidade ao mercado a partir dos anos 1990, a universidade passou a ter caráter operacional. Regida por contratos de gestão, avaliada por índices de produtividade, pensada para ser flexível, esta universidade está voltada para dentro de si mesma. É visível o aumento de horas-aula, a diminuição do tempo para mestrados e doutorados (BIANCHETI; MACHADO, 2002), a avaliação pela quantidade de publicações, congressos, multiplicação de comissões e relatórios etc. (CHAUÍ, 1999). Ainda segundo Chaú, nesta universidade, ocorre a desvalorização da docência; afinal, a formação cedeu espaço para o treinamento e adestramento. Nesse caso, podemos perguntar: será que a desvalorização da docência pode ser entendida pela valorização da pesquisa? O que é a pesquisa em uma universidade operacional sob a ideologia pós-moderna?

Para a ideologia pós-moderna, a razão, a verdade e a história são mitos. Em tempos também de "recuo da teoria" 
(MORAES, 2003), a pesquisa nesta universidade apenas pode ser entendida como posse de instrumentos para intervir e controlar alguma coisa. Pesquisa não é o conhecimento de alguma coisa. Nesse locus, não há tempo para a reflexão, a crítica, o exame de conhecimentos instituídos, sua mudança ou sua superação. A pesquisa se reduz à delimitação estratégica de um campo de intervenção e controle em que somente pode ser avaliada em termos de custo-benefício, regulada pela lógica da produtividade, que avalia o tempo, o custo e o quanto foi produzido (CHAUÍ, 1999). Esta universidade, portanto, não cria e não forma pensamento. Ela destrói a curiosidade e a admiração que levam à descoberta do novo e, ainda, reduz a nada a pretensão de transformação histórica como ação de homens e mulheres em condições materialmente determinadas:

Se por pesquisa entendermos a investigação de algo que nos lança na interrogação, que nos pede reflexão, crítica, enfrentamento com o instituído, descoberta, invenção e criação; se por pesquisa entendermos o trabalho do pensamento e da linguagem para pensar e dizer o que ainda não foi pensado, nem dito; se por pesquisa entendermos uma visão compreensiva de totalidades e sínteses abertas que suscitam a interrogação e a busca; se por pesquisa entendermos uma ação civilizatória contra a barbárie social e política, então, é evidente que não há pesquisa na universidade operacional. (CHAUÍ, 1999, p. 222).

Contudo, não parece ter sido a universidade operacional o locus principal da formação dos docentes sujeitos de nossa pesquisa. O perfil acadêmico que predominou nas instituições nas quais os docentes obtiveram a titulação, foi o das universidades que integram ensino, pesquisa e extensão. Esse aspecto ficou explícito nas características amplas e generalistas dos editais que concursam os professores que ingressaram no IFPR - Campus Palmas, no ano de 2010, conforme veremos no item que segue.

\section{TRABALHO DOCENTE E ACUMULAÇÃO FLEXÍVEL}

Outro aspecto analisado em nossa pesquisa foi a titulação/formação exigida dos docentes que participaram do Concurso Público para docentes no IFPR - Campus Palmas, no ano de 2010. Ao realizar uma leitura dos diferentes editais, salta aos olhos o caráter amplo e genérico da titulação/formação solicitada nas diversas áreas do conhecimento, conforme podemos verificar na seguinte quadro: 
Quadro 1 - Editais/áreas do conhecimento e titulação/formação exigida

\begin{tabular}{|c|c|c|}
\hline Edital & Áreas do conhecimento & Titulação/formação exigida \\
\hline \multirow[t]{7}{*}{$\mathrm{N}^{\mathrm{o}} 006$} & Ciências da Natureza - Química. & $\begin{array}{l}\text { Licenciatura em Química ou Ciências - Habilitação em Quí- } \\
\text { mica com Especialização ou Mestrado na área. }\end{array}$ \\
\hline & Ciências Exatas - Matemática. & $\begin{array}{l}\text { Licenciatura em Matemática com Especialização ou Mestra- } \\
\text { do na Área. }\end{array}$ \\
\hline & Ciências Humanas - Pedagogia & $\begin{array}{l}\text { Graduação em Pedagogia com Especialização ou Mestrado } \\
\text { na Área. }\end{array}$ \\
\hline & Ciências da Natureza - Biologia & $\begin{array}{l}\text { Licenciatura em Biologia ou Ciências Biológicas ou Ciências } \\
\text { - Habilitação em Biologia com Especialização ou Mestrado } \\
\text { na área }\end{array}$ \\
\hline & Recursos Naturais - Agrofloresta & $\begin{array}{l}\text { Graduação em Engenharia Florestal ou em Ciências Agrá- } \\
\text { rias ou em Meio Ambiente, com Especialização ou Mestra- } \\
\text { do na área. }\end{array}$ \\
\hline & $\begin{array}{l}\text { Gestão e Negócios - Administração de } \\
\text { Empresas }\end{array}$ & $\begin{array}{l}\text { Graduação em Administração de Empresas com Especializa- } \\
\text { ção ou Mestrado na área }\end{array}$ \\
\hline & Gestão e Negócios - Ciências Contábeis & $\begin{array}{l}\text { Graduação em Ciências Contábeis com Especialização ou } \\
\text { Mestrado na área. }\end{array}$ \\
\hline
\end{tabular}

No 008 Ciências da Saúde - Educação Física Ciências da Saúde - Enfermagem

Ciências da Saúde - Farmácia e Bioquímica

\section{No 013 Ciências Jurídicas}

Ciências Tecnológicas - Arquitetura

Ciências Tecnológicas - Engenharia Civil Informação e Comunicação - Informática

Linguagens, Códigos e suas Tecnologias
- Letras.
Produção Cultural e Design - Artes
Ciências Agrárias - Agronomia
Ciências Agrárias - Agronomia

No 033 Ciências da Natureza - Química
Licenciatura em Educação Física com especialização na área Graduação em Enfermagem com especialização em Enfermagem ou Saúde Coletiva.

Graduação em Farmácia e/ou Bioquímica com especialização na área ou Saúde Coletiva

Graduação em Direito, com especialização e ou mestrado na área.

Graduação em Arquitetura e especialização na área.

Graduação em Engenharia Civil e especialização na área.

Graduação em Informática, Ciência da Computação. Engenharia da Computação, Tecnologia em Informática e demais Graduações na área de Informática, com especialização ou mestrado em áreas afins.

Licenciatura em Letras - Português/Inglês com especialização ou mestrado na área.

Graduação em Licenciatura em Artes, Artes Visuais, Educação Artísticas, com especialização ou mestrado na área.

Graduação em Agronomia, Especialista ou Mestre em Solos ou com conhecimentos comprovados em Solos.

Graduação em Agronomia, com Especialização ou Mestrado em Produção Vegetal, Fitossanidade ou áreas afins.

Licenciatura em Química ou Ciências - Habilitação em Química, obtidos na forma da lei e especialização na área.

Fonte: Dados organizados pelos autores com base nos Editais $n^{\circ}$ 006/2010, $n^{\circ}$ 008/2010, $\mathrm{n}^{\mathrm{o}}$ 013/2010 e $\mathrm{n}^{\mathrm{o}}$ 033/2010 do PROGEPE (IFPR, 2010a, 2010b, 2010c, 2010d).

Com algumas exceções, como é o caso da Agronomia, por exemplo, a maior parte dos editais exigiu uma amplitude na titulação para as diferentes subáreas do conhecimento. Contudo, esse caráter generalista não se refere apenas aos requisitos de titulação, como também da formação exigida, que enfoca claramente a escolha do perfil generalista para o trabalho docente. Esse aspecto pode ser visualizado a partir dos conteúdos programáticos apresentados pelos 
editais. A título de ilustração apresentamos a seguir os 10 (dez) itens (conteúdo programático) do Edital n ${ }^{0}$ oo6/2010 do PROGEPE/IFPR, que selecionou professores para a área de conhecimento: Ciências Humanas - Pedagogia:

1. LDB E POLÍTICAS PARA A EDUCAÇÃO NO BRASIL. Elementos sócio-históricos [sic] da Legislação do Ensino Brasileiro. Políticas públicas educacionais. Gestão democrática e participativa. Desafios da democratização da educação no Brasil;

2. PROCESSO DE ESCOLARIZACÃO E PARADIGMAS CURRICULARES NO BRASIL. Teorias do currículo e suas implicações para a prática pedagógica. Concepções de ensino e aprendizagem. Currículo e diversidade. Tecnologia e currículo;

3. PROJETO POLÍTICO PEDAGÓGICO E A ORGANIZAÇÃO DE PROPOSTAS CURRICULARES. Desafios à gestão democrática da escola. Currículo e a formação continuada de professores. Modalidades de integração curricular e suas implicações para a prática pedagógica. Tempos e espaços na organização curricular. Gestão democrática e coordenação político-pedagógica da escola;

4. DIDÁTICA COMO CAMPO DE CONHECIMENTO NA FORMAÇÃO DE PROFESSORES. Fundamentos teórico-conceituais da didática. Diferentes objetos de estudo da didática. Desafios contemporâneos da organização didático-pedagógica da escola. Relação entre saberes e o cotidiano escolar. As dimensões do processo didático na ação docente; 5. PLANEJAMENTO E AVALIAÇÃO DO PROCESSO PEDAGÓGICO. Concepções de planejamento e avaliação. Planejamento participativo e prática pedagógica. As práticas avaliativas no cotidiano escolar. Planejamento, currículo e avaliação no contexto pedagógico da escola. Avaliação e aprendizagem; 6. CORRENTES FILOSÓFICAS E SUAS IMPLICAÇÕES PEDAGÓGICAS. Concepções/ tendências da educação no Brasil. Educação: produção e reprodução. Conceitos, meios, fins e objetivo da educação. Ética e educação. Agentes do processo educativo;

7. EDUCAÇÃO, DIVERSIDADE E PROCESSOS INCLUSIVOS NO CONTEXTO ESCOLAR. Concepções/conceito de diversidade e inclusão. Sujeitos, contexto e cotidiano escolar. Desafios à prática pedagógica inclusiva. Fundamentos teórico-metodológicos da educação para a diversidade. Educação de jovens e adultos;

8. EDUCAÇÃO E CIDADANIA. Identidades. Culturas. Gênero e etnias. Estatuto da criança e do adolescente. Educação e direitos humanos;

9. EDUCAÇÃO, TRABALHO, CIÊNCIA, TECNOLOGIA E CULTURA. Concepção/ conceito(s) de trabalho. As relações entre educação e trabalho. As relações entre educação 


\footnotetext{
7 De acordo com Holzmann (2011), o toyotismo designa o modo de organizar os processos de trabalho e de produção, idealizado e introduzido na fábrica japonesa da Toyota, no Japão, nos anos de 1950. Contudo, foi amplamente difundido a partir do final da década de 1970, constituindo um dos recursos da estratégia capitalista para fazer frente à crise da produção em massa fordista. Embora inicialmente implantado no ramo automobilístico, o toyotismo foi adotado em todos os setores industriais e seus princípios, métodos e programas mostraram-se aplicáveis também ao setor de serviços.
}

e tecnologia. As relações entre ciência e tecnologia. A educação nos diferentes modos de produção;

10. TECNOLOGIAS DE INFORMAÇÃO E COMUNICAČ̃̃O NO CONTEXTO DO TRABALHO PEDAGÓGICO DA ESCOLA. As mediações tecnológicas contemporâneas e o ensino. As novas tecnologias de informação e comunicação (TIC) no contexto escolar. Mídia e educação. Mídia e formação sociocultural. Desafios da educação escolar frente às tecnologias de informação e comunicação. (IFPR, 2010a, 2010b, 2010c, 2010d).

O perfil generalista exigido dos pedagogos vai ao encontro do perfil generalista exigido dos demais profissionais no mundo do trabalho. Contudo, se analisarmos, pela perspectiva da formação há uma contradição evidente nesse processo. Ao mesmo tempo em que os cursos de pós-graduação stricto sensu afunilam verticalmente a formação de mestres e doutores, por meio de diferentes linhas de pesquisa, favorecendo o conhecimento especializado em determinada área do conhecimento, os editais do concurso exigem profissionais com uma formação ampla, recrutando professores trabalhadores, que apresentam características nitidamente generalistas.

Esse aspecto da formação docente, de certo modo, "especialista", mas com a exigência cada vez maior de um perfil de trabalhador docente mais "generalista", nos remete às mudanças mais amplas ocorridas no mundo do trabalho. Com a implantação do sistema toyotista ${ }^{7}$ - Benjamin Coriat (1994) chama esta nova organização do trabalho de toyotismo, uma referência à empresa Toyota (ou ohnismo-Ohno, engenheiro da Toyota) -, ocorrido a partir dos anos de 1970, e que se efetivou, em meados da década de 1990, no Brasil, houve uma significativa reestruturação no modo de produção capitalista, desencadeando mudanças no modo de organização da produção. A partir de então, não se dispensou o trabalhador especialista, mas passou-se a exigir novas habilidades para a inserção profissional, preferindo-se um perfil de trabalhador cada vez mais generalista.

O caráter generalista do trabalhador se articula ao que é característico desta nova organização do processo de trabalho: a produção enxuta. Não é a produção que define o consumo, mas é o consumo que define a produção. Ou seja, somente será produzido aquilo que for consumido. Assim: "Enquanto no taylorismo-fordismo a direção é do estoque para o consumidor, no toyotismo é do consumidor para o estoque" (TURMINA; BIANCHETTI, 2002/2003, p. 54). Consequentemente, a quantidade de trabalho vivo também será enxuta, reduzida. Segundo Gounet (1999, p. 29) o toyotismo é "[...] um sistema de organização da produção baseado em uma resposta imediata às variações da demanda e que exige, portanto, uma organização flexível do trabalho (inclusive dos trabalhadores) e integrada”. 
${ }^{8}$ De acordo com Sennett (2007), a palavra "flexibilidade" passou a fazer parte da língua inglesa ainda no século XV e seu sentido derivou originalmente da simples observação de que, embora uma árvore se dobrasse ao vento, seus galhos sempre voltavam à posição normal. Assim, "flexibilidade" designa essa capacidade de ceder e recuperarse da árvore, o teste e restauração de sua forma. Falando em termos ideais, o comportamento humano flexível deve ter a mesma força tênsil: ser adaptável a circunstâncias variáveis, mas não quebrado por elas. A esse respeito esse autor conclui que a sociedade "[...] hoje busca meios de destruir os males da rotina com a criação de instituições mais flexíveis. As práticas de flexibilidade, porém, concentram-se mais nas forças que dobram as pessoas" (p. 53)
No que diz respeito ao processo de trabalho, o toyotismo elimina a relação operador-máquina, como é típico no processo de produção fordista, e instaura o trabalho em equipe, operando em uma célula de manufatura, conforme esclarece Holzmann (2011, p. 428):

No interior da célula não há uma demarcação rígida das atribuiç̃es de cada trabalhador. Eles devem ser suficientemente flexíveis para poder desempenhar cada uma das tarefas executadas na célula e devem ser portadores de habilidades ampliadas em relação às requisitadas no sistema fordista, no qual elas são restritas ao posto de trabalho que cada trabalhador ocupa. (grifos nossos).

A flexibilidade ${ }^{8}$, portanto, é um dos elementos mais relevantes do modelo toyotista, integrada como princípio na organização da produção e do processo de trabalho, exigida dos trabalhadores e manifesta na variação dos produtos e na rapidez de sua inovação. Harvey (2001, p. 140) intitula acumulação flexível para a nova forma de acumulação capitalista:

Ela se apoia na flexibilidade dos processos de trabalho, dos mercados de trabalho, dos produtos e padrões de consumo. Caracteriza-se pelo surgimento de setores de produção inteiramente novos, novas maneiras de fornecimento de serviços financeiros, novos mercados e, sobretudo, taxas altamente intensificadas de inovação comercial, tecnológica e organizacional. A acumulação flexível envolve rápidas mudanças dos padrões do desenvolvimento desigual, tanto entre setores como entre regiões geográficas, criando, por exemplo, um vasto movimento no emprego no chamado "setor de serviços", bem como conjuntos industriais completamente novos em regiões até então subdesenvolvidas.

A reestruturação na organização social do trabalho demanda um perfil profissional fundamentado no "saber ser", "saber aprender" e "saber fazer". Nesse sentido, vem à tona a questão do trabalhador polivalente, detentor de novos conhecimentos (níveis mais elevados de escolaridade), que saiba trabalhar em equipe e que tenha uma capacidade de identificar e resolver problemas bem como habilidades técnicas e capacidade de se ajustar à flexibilidade da produção (LAPIS, 2011). Por esse viés, o trabalhador está submetido à seguinte forma de trabalho:

[...] múltiplas tarefas; pagamento pessoal (sistema detalhado de bonificações); eliminação da demarcação de tarefas; longo treinamento no trabalho; organização mais horizontal no trabalho; aprendizagem no trabalho; ênfase na co-responsabilidade [sic] do trabalhador; grande segurança no emprego 
${ }^{8}$ Apesar de os governos neoliberais defenderem a privatização generalizada e a redução dos gastos públicos com as políticas sociais, essas mudanças não foram tão significativas nos países europeus e também nos estados Unidos, que continuaram a manter áreas estratégicas da produção sob propriedade e controle do Estado e uma extensão rede de proteção social" (NASCIMENTO; SILVA; ALGEBAILE, 2002, p. 92). Nesse sentido, Sader (apud NASCIMENTO; SILVA; ALGEBAILE, 2002, p. 92) afirma que "[...] o neoliberalismo é um remédio amargo que os países do Primeiro Mundo não tomam na dosagem que propõem ao Terceiro Mundo ou, se o tomaram, já passaram a corrigir seus rumos $[\ldots] "$. para trabalhadores centrais (emprego perpétuo). Nenhuma segurança no trabalho e condições de trabalho ruins para trabalhadores temporários. (HARVEY, 2001, p. 167-168).

A demanda por trabalhadores flexíveis, "aptos a desempenharem um amplo leque de tarefas no processo produtivo" (HOLZMANN, 2011, p. 428), também pode ser claramente verificada na situação dos editais dos concursos que selecionaram os docentes do IFPR - Campus Palmas, no ano de 2010.

Logo, essa demanda pode ser entendida somente a partir do movimento do capital que ora demanda trabalhadores especialistas, ora generalistas. A burguesia - detentora dos meios de produção no modo de produção capitalista - assume um caráter cosmopolita e, conforme asseveram Karl Marx e Friedrich Engels (2002, p. 48), “[...] não pode existir sem revolucionar continuamente os instrumentos de produção e, por conseguinte, as relações de produção, portanto, todo o conjunto de relações sociais".

É importante destacarmos que, embora o Estado moderno esteja orientado pela lógica do modo de produção capitalista, constitui-se em um Estado burguês onde o poder político é, também, "um comitê para administrar os negócios comuns de toda a classe burguesa" (MARX; ENGELS, 2002, p. 47). Dessa forma, podemos afirmar que, no Brasil de hoje,

[...] afigura-se como condensação de relações de força entre classes e frações de classes. Mesmo com a ampla hegemonia da proposta burguesa de sociedade e de educação no Brasil nos dias atuais, o Estado, ao definir suas políticas, leva em conta os imperativos do capital em seu conjunto e também das outras classes sociais, e não apenas as demandas imediatas de um capitalista singular ou de fração do capital. (NEVES, 2002, p. 219).

Neste sentido, o Estado, na formulação de suas políticas de contratação de professores, visando a atender às demandas específicas e mais amplas da sociedade, assume característica enxuta. Percebe-se um enxugamento em relação ao número de vagas ofertadas, via concurso público, para suprir as necessidades da instituição estudada.

Com as mudanças ocorridas na produção, o (neo) liberalismo ${ }^{8}$ (re)assume a função da "nova" ideologia do capital no sentido de minimizar a função do Estado em relação aos gastos sociais e à intervenção junto ao mercado, e maximizar legalmente a lógica produtiva. A descentralização das responsabilidades públicas para a sociedade civil tornou o Estado (enxuto) brasileiro inserido na lógica global devido ao caráter universalizante do capitalismo (MONTAÑO, 1999). Portanto, o Estado brasileiro, a partir do momento que se insere na nova forma de reestruturação produtiva - que se caracteriza entre outros pontos pela 
implementação de novas tecnologias e formas de gestão e contratação da força de trabalho em todo o âmbito da empresa -, fundamenta suas ações em tal lógica.

A partir dessa característica de gestão pública no âmbito da contratação de docentes, cabe ao professor assumir disciplinas significativamente distintas de sua formação acadêmica. O trabalhador docente deve, portanto, desenvolver múltiplas funções. Este é o fardo que o trabalhador carrega como resultado de um Estado, mínimo para as políticas sociais - neste caso, a educação - e, máximo para as lógicas do capital. Segundo o estudo realizado, a ideia é contratar um número reduzido de professores via concurso público, a fim de que atendam à demanda da instituição sem onerar os cofres públicos. As demais lacunas são preenchidas pela contratação de trabalhadores (professores) temporários, outra característica do modelo de acumulação flexível; porém, este é um estudo que demanda outras pesquisas, pois, no momento, tal discussão se distancia dos objetivos propostos.

\section{CONSIDERAÇÕES FINAIS}

Constatamos que a trajetória acadêmica dos docentes que assumiram o concurso público no IFPR - Campus Palmas, no ano de 2010 se deu, na sua maioria, em instituições públicas que, prevalentemente, integram em suas atividades formativas o ensino, pesquisa e extensão. Tendo em vista o grau de exigência que está atrelada à disputa por vagas em um concurso para docente em instituições públicas federais, percebemos que a formação/trajetória acadêmica do profissional que se sujeita a prestar este tipo de seleção deve ser consistente. Esses dados corroboram com o estudo de Bourdieu (2005, p. 78): "[...] ao conferir ao capital cultural possuído por determinado agente de um reconhecimento institucional, o certificado escolar permite, além disso, a comparação entre os diplomados".

Consideramos também que, embora inseridas em uma sociedade regida pelo modo de produção capitalista, as instituições públicas se diferenciam das instituições privadas de cunho mercadológico. Assumindo a indissociabilidade entre ensino e pesquisa, tais instituições contribuem para a formação de um perfil de docentes que assumiram o concurso já referido.

Outra questão constatada é a exigência explicitada em edital de que o trabalhador docente tenha característica generalista. Nesse sentido, alinhado às mudanças ocorridas no mundo do trabalho, no Brasil, nas últimas décadas, verificou-se que esse caráter generalista não se refere apenas aos requisitos de titulação, como também da formação exigida (habilidades), que enfoca claramente a escolha do perfil generalista para o trabalho docente.

Assim, é possível vislumbrarmos uma contradição, pois, ao mesmo tempo em que os cursos de pós-graduação stricto sensu afunilam verticalmente a formação docente, 
por meio das linhas de pesquisa, favorecendo o conhecimento especializado em determinada área, os editais dos concursos analisados exigiram profissionais com uma formação ampla, recrutando professores trabalhadores, que apresentam características nitidamente generalistas.

Cabe assinalarmos, finalmente, que o Estado está umbilicalmente atrelado ao modo de produção capitalista. Ou seja, o Estado faz parte desse processo de reestruturação produtiva, na medida em que, por um lado, exerce a função regulatória para que as mudanças aconteçam; por outro, ele próprio precisa se adequar às mudanças do mundo do trabalho. Por conseguinte, a contratação de professores, via concurso público, também seguiu essa tendência.

\section{REFERÊNCIAS}

ALVES, Vânia Maria. Formação e trabalho de pesquisadores em educação: um estudo dos processos de institucionalização da pesquisa em IES “emergentes". 2008. 308 f. Tese (Doutorado em Educação) - Programa de Pós-graduação em Educação, Universidade Federal de Santa Catarina, Florianópolis, 2008.

BIANCHETI, Lucídio; MACHADO, Ana Maria (Org.). A bússola do escrever: desafios e estratégias na orientação de teses e dissertações. São Paulo: Cortez, 2002.

BOGONI, Rosa Tereza Hentz. Universidade e Estado: os estratégicos limites da pesquisa. Caçador: Gráfica Valkart, 2002.

BOURDIEU, Pierre. Os três estados do capital cultural. In: NOGUEIRA, Maria A.; CATANI, Afrânio (Org.). Escritos de educação. 7. ed. Petrópolis: Vozes, 2005. pp. 39-64.

BOURDIEU, Pierre. A distinção: crítica social do julgamento. Tradução de Daniela Kern; Guilherme J. F. Teixeira. 1. reimp. São Paulo: Edusp; Porto Alegre: Zouk, 2008.

BRASIL. Lei $n^{0}$ 4.024, de 20 de dezembro de 1961. Fixa as Diretrizes e Bases da Educação Nacional. Diário Oficial da União, Brasília, DF, 27 dez. 1961. Disponível em: <http://www.planalto.gov.br/ccivil_03/leis/L4024. htm $>$. Acesso em: 20 jun. 2015.

BRASIL. Lei $n^{0}$ 9.394, de 20 de dezembro de 1996. Estabelece as diretrizes e bases da educação nacional. Diário Oficial da União, Brasília, DF, 23 dez. 1996. Disponível em: <http://www.planalto.gov.br/ccivil_03/leis/L9394. htm>. Acesso em: 21 jun. 2015.

BRASIL. Lei $\mathrm{n}^{0}$ 11.892, de 29 de dezembro de 2008. Institui a Rede Federal de Educação Profissional, Científica e Tecnológica, cria os Institutos Federais de Educação, 
Ciência e Tecnologia, e dá outras providências. Diário Oficial da União, Brasília, DF, 30 dez. 2008. Disponível em: <http://www.planalto.gov.br/ccivil_03/_ato20072010/2008/lei/l11892.htm>. Acesso em: 20 jun. 2015.

BRASIL. Ministério da Educação. Secretaria de Educação Superior. Portaria ${ }^{0} 728$, de 14 de junho de 2010. Diário Oficial da União, Brasília, DF, 15 jun. 2010. Disponível em: <http://www.jusbrasil.com.br/diarios/5661353/pg-9-secao-1-diario-oficial-da-uniao-dou-de-15-06-2010>. Acesso em: 22 jun. 2015.

CHAUÍ, Marilena. A universidade em ruínas. In: TRINDADE, Hélgio (Org.) Universidade em ruínas: na república dos professores. Petrópolis: Vozes; Rio Grande do Sul: CIPEDES, 1999. p. 211-222.

CORIAT, Benjamin. Pensar pelo avesso: o modelo japonês de trabalho e organização. Rio de Janeiro: Revan; UFRJ, 1994.

GOUNET, Thomas. Fordismo e toyotismo na civilização do automóvel. São Paulo: Boitempo Editorial, 1999.

HARVEY, David. Condição pós-moderna. 10. ed. São Paulo: Loyola, 2001.

HOLZMANN, Lorena. Toyotismo. In: CATTANI, Antonio D.; HOLZMANN, Lorena (Org.). Dicionário de trabalho e tecnologia. 2. ed. rev. e ampl. Porto Alegre: Zouk, 2011. p. 426.

LAPIS, Naira Lima. Acumulação Flexível. In: CATTANI, Antonio D.; HOLZMANN, Lorena (Org.). Dicionário de trabalho e tecnologia. 2. ed. rev. e ampl. Porto Alegre: Zouk, 2011. p. 27.

LIMA, Madalena Mergen. Contextualização das faculdades de Palmas: uma retrospectiva de sua caminhada. Consciência, Palmas, v. 11, n. 1, p. 9-38, jan./jun. 1997.

MARX, Karl; ENGELS, Friedrich. Manifesto do Partido Comunista. São Paulo: Martin Claret, 2002.

MONTAÑO, Carlos. Das "lógicas do Estado" às "lógicas da sociedade civil": Estado e "terceiro setor" em questão. Serviço Social e Sociedade, n. 59. São Paulo, 1999. p. 47-79.

MORAES, Maria Célia Marcondes de. de Recuo da teoria. In: MORAES, Maria Célia Marcondes de (Org.). Iluminismo às avessas: produção de conhecimento e políticas de formação docente. Rio de Janeiro: DP\&A, 2003. p. 151-169.

NASCIMENTO, Alexandre do; SILVA, Andréia Ferreira da; ALGEBAILE, Maria Emílio Bertino. Estado, Mercado 
e Trabalho: Neoliberalismo e políticas sociais. In: NEVES, Lúcia Maria Wanderlei (Org.). O empresariamento da educação: novos contornos do Ensino Superior no Brasil dos anos 1990. São Paulo/SP: Xamã, 2002. p. 85-104.

NEVES, Lúcia Maria Wanderlei (Org.). O empresariamento da educação: novos contornos do Ensino Superior no Brasil dos anos 1990. São Paulo: Xamã, 2002.

NEVES, Lúcia Maria Wanderlei; FERNANDES, Raposo Fernandes. Política neoliberal e educação superior. In: NEVES, Lúcia Maria Wanderlei (Org.). O empresariamento da educação: novos contornos do ensino superior no Brasil dos anos 1990. São Paulo: Xamã, 2002. p. 21-40.

NEVES, Lúcia Maria Wanderlei; PRONKO, Marcela Alejandra. O mercado do conhecimento e o conhecimento para o mercado: da formação para o trabalho complexo no Brasil contemporâneo. Rio de Janeiro: EPSJV, 2008.

INSTITUTO FEDERAL DO PARANÁ. Pró-Reitoria de Gestão de Pessoas (PROGEPE). Edital no oo6/2010 - Concurso Público para provimento de cargos de professor da Carreira do Ensino Básico, Técnico e Tecnológico, Classe "D I", Nível 1, sob o Regime Jurídico Único dos Servidores Públicos Civis da União, Autarquias e das Fundações Públicas Federais em conformidade com a Lei no 8.112/1990, Decreto $n^{0}$ 6.944/2008, Lei $n^{0} 11.784 / 2008$ e Resolução $\mathrm{n}^{0}$ 003/2009 - Conselho Superior/IFPR. Curitiba: Instituto Federal do Paraná, 2010a.

INSTITUTO FEDERAL DO PARANÁ. Pró-Reitoria de Gestão de Pessoas (PROGEPE). Edital no oo8/2010 - Concurso Público para provimento de cargos de professor da Carreira do Ensino Básico, Técnico e Tecnológico, Classe "D I", Nível 1, sob o Regime Jurídico Único dos Servidores Públicos Civis da União, Autarquias e das Fundações Públicas Federais em conformidade com a Lei ${ }^{0} 8.112 / 1990$, Decreto $n^{0}$ 6.944/2008, Lei ${ }^{0} 11.784 / 2008$ e Resolução $\mathrm{n}^{\mathrm{o}}$ 003/2009 - Conselho Superior/IFPR. Curitiba: Instituto Federal do Paraná, 2010b.

INSTITUTO FEDERAL DO PARANÁ. Pró-Reitoria de Gestão de Pessoas (PROGEPE). Edital no o13/2010 - Concurso Público para provimento de cargos de professor da Carreira do Ensino Básico, Técnico e Tecnológico, Classe "D I", Nível 1, sob o Regime Jurídico Único dos Servidores Públicos Civis da União, Autarquias e das Fundações Públicas Federais em conformidade com a Lei no 8.112/1990, Decreto $n^{0}$ 6.944/2008, Lei ${ }^{0}$ 11.784/2008 e Resolução $\mathrm{n}^{0}$ 003/2009 - Conselho Superior/IFPR. Curitiba: Instituto Federal do Paraná, 2010c. 
INSTITUTO FEDERAL DO PARANÁ. Pró-Reitoria de Gestão de Pessoas (PROGEPE). Edital no o33/2010 - Concurso Público para provimento de cargos de professor da Carreira do Ensino Básico, Técnico e Tecnológico, Classe "D I", Nível 1, sob o Regime Jurídico Único dos Servidores Públicos Civis da União, Autarquias e das Fundações Públicas Federais em conformidade com a Lei ${ }^{0}$ 8.112/1990, Decreto $n^{0}$ 6.944/2008, Lei $n^{0} 11.784 / 2008$ e Resolução $\mathrm{n}^{0}$ 003/2009 - Conselho Superior/IFPR. Curitiba: Instituto Federal do Paraná, 2010d.

SAVIANI, Dermeval. Ensino público e algumas falas sobre universidade. São Paulo: Cortez: Autores Associados, 1985 .

SENNETT, Richard. A corrosão do caráter: conseqüências pessoais do trabalho no novo capitalismo. 12. ed. Rio de Janeiro: Record, 2007.

SILVA Jr. João dos Reis. Reforma do Estado e da educação no Brasil de FHC. São Paulo: Xamã, 2002.

SOBRINHO, José Dias. Avaliação e privatização do Ensino Superior. In: TRINDADE, Hélgio (Org.). Universidade em ruínas: na república dos professores. Petrópolis: Vozes/Rio Grande do Sul: CIPEDES, 1999. p. 61-72.

TURMENA, Leandro. O público, o privado e o Estado sob a lógica do capital: a expansão do Ensino Superior no Sudoeste do Paraná. 149 f. Dissertação (Mestrado em Educação) - Universidade Estadual de Ponta Grossa, Ponta Grossa, 2009.

TURMINA, Adriana; BIANCHETTI, Lucídio. Especialistas ou generalistas? As origens desse dilema e os seus desdobramentos para a práxis dos orientadores e dos supervisores educacionais. Prospectiva, Porto Alegre, n. 27, p. 47-59, 2002/2003.

VALLE, Ione Ribeiro. Pierre Bourdieu: a pesquisa e o pesquisador. In: BIANCHETTI, Lucídio; MEKSENAS, Paulo (Org.). A trama do conhecimento: teoria, método e escrita em ciência e pesquisa. Campinas: Papirus, 2008. p. 95-117. 